\title{
Fraksiyonel Dereceli Kaotik Lorenz Sistemi'nin Devre Sentezi
}

\author{
İbrahim Ethem Saçu ${ }^{1 *}$, Nimet Korkmaz ${ }^{2}$ \\ 1* Erciyes Üniversitesi, Klinik Mühendisliği Arş. ve Uyg. Merkezi (ERKAM), Kayseri, Türkiye, (ORCID: 0000-0002-8627-8278), iesacu@erciyes.edu.tr \\ ${ }^{2}$ Erciyes Üniversitesi, Klinik Mühendisliği Arş. ve Uyg. Merkezi (ERKAM), Kayseri, Türkiye (ORCID: 0000-0002-7419-1538), nimetdahasert@erciyes.edu.tr
}

(2nd International Conference on Access to Recent Advances in Engineering and Digitalization (ARACONF)-10-12 March 2021)

(DOI: 10.31590/ejosat.901025)

ATIF/REFERENCE: Saçu, İ E. \& Korkmaz, N. (2021). Fraksiyonel Dereceli Kaotik Lorenz Sistemi'nin Devre Sentezi. Avrupa Bilim ve Teknoloji Dergisi, (24), 42-46.

\section{$\ddot{O} \mathbf{z}$}

Bu çalışmada fraksiyonel dereceli Lorenz Sistemi'nin devre sentezinde; fraksiyonel dereceli diferansiyel denklemlerin integrasyon işlemini gerçeklemek için standart kapasitörler kullanmak yerine R-C taklit devrelerinin kullanılmış ve bu devrelerin tasarım aşamaları üzerinde durulmuştur. Fraksiyonel dereceli sistemin R-C taklit devreleri ile tasarımı için, Matsuda yaklaşıklık metodu ile üçüncü dereceden transfer fonksiyonu elde edilmiş̧ir. Elde edilen bu fonksiyon FOSTER-I R-C ağına dönüştürülerek, kaotik Lorenz Sistemi'nin devre çözümünde kullanılmıştır. Fraksiyonel dereceli Lorenz Sistemi'nin devre çözümü için tasarlanan sistemin doğrulaması SPICE devre simülasyonu ile yapılmıştır.

Anahtar Kelimeler: Kaotik Lorenz Sistemi, Fraksiyonel Kapasitör, Devre Sentezi, Matsuda Yaklaşıklık Yöntemi, FOSTER-I Ağı.

\section{The Circuit Synthesis of the Fractional-Order Chaotic Lorenz System}

\begin{abstract}
In this study, the R-C emulator circuits have been used instead of using standard capacitors in the circuit synthesis of the fractionalorder Lorenz System and the design stages of these circuits have been emphasized. A third order transfer function has been obtained by Matsuda approximation method in order to get design of the fractional-order system with R-C emulator circuits. This obtained function has been transformed into FOSTER-I R-C network and this network structure has been used in the circuit solution of the chaotic Lorenz System. The verification of the system, which is designed for the circuit solution of the fractional-order Lorenz System, has been made by SPICE circuit simulation.
\end{abstract}

Keywords: Chaotic Lorenz System, Fractional Capacitor, Circuit Synthesis, Matsuda Approximation Method, FOSTER-I Network. 


\section{Giriş}

Düzensizliğin düzeni şeklinde tanımlanan kaotik sistemlerin en temel karakteristikleri, başlangıç şartlarına duyarlılık ve geniş güç spektrumudur. Bu kavram literatüre ilk kez Fransız filozof Henry Poincare'in yaptığı astronomi çalışmaları ile 20. yüzyılın başlarında sunulmuş olup, kompleks sistemler üzerinde yapılan analizlerle ilgili çalışmalarda kullanılmıştır [1]. Bu sistemlerde; başlangıç koşullarındaki küçük farklılıklar, sistem çıkışında büyük değişikliklere sebep olmakta ve bu sebeple sistem çıkışının tahmin edilebilirliği zorlaşmaktadır. Öyle ki bazı durumlarda kompleks davranış sergilemeyen dinamik sistemlerde meydana gelen küçük parametre değişimleri, sistemi kaotik davranışa sürüklenmektedir.

Günümüzde kaos konusu; tıp, fizik, kimya, biyoloji gibi temel bilimler, mühendislik ve meteoroloji, ekonomi gibi farklı alanlarda sıklıkla çalışılmaktadır. Küresel 1sınma konusunda karbon emisyonu iklim değişikliği gibi etkenlerin, ekonomi üzerinde faiz oranlarının ve borsadaki dalgalanmalarının ya da popülasyon devamlılığı için çevre şartlarının ele alındığı ve düzensizliğin hakim olduğu bilimsel çalışmalarda; bu süreçlerin devamında meydana gelebilecek sonuçların öngörülmesi için eldeki verilerin analizine ve sonuçların yorumuna ihtiyaç vardır. Doğrusal olmayan bu sistemlerin analiz süreçlerinde klasik yöntemlerden yararlanılarak elde edilen sonuçlar beklentileri karşılamamaktadır. Bu sebeple kaotik sistemlerin analizi için yeni yöntemlerin kullanılması gündeme gelmiştir [2].

Doğrusal olmayan sistemlerin en yaygın uygulama alanlarından biri olan kaotik sistemler; ayrık zamanlı fark denklemleri ile tanımlanabildiği gibi, diferansiyel denklem takımları ile de ifade edilebilmektedir. Bunların yanı sıra, son zamanlarda fraksiyonel tanımlı genelleştirilmiş doğrusal olmayan sistemler üzerine de birçok çalışma yapılmaktadır. Fraksiyonel hesaplama, klasik matematiksel hesaptan farklı olarak diferansiyel denklemlerin derecesinin tam say1 olmayabileceğini belirtmekte ve daha genel bir tanımlama ortaya koymaktadır. Böylece herhangi bir diferansiyel denklemin derecesi tam say1, kesirli sayı hatta kompleks sayı olabilmektedir. Kaotik sistemlerin uygulama alanlarına benzer şekilde, fraksiyonel hesaplamalı sistemler de mühendislik, biyoloji, kontrol teorisi gibi alanlarda kullanılabilmektedir.

Fraksiyonel sistemlerin en önemli avantajlarından biri sistem modelleme çalışmalarında daha ayrıntılı tanımlamalar sağlamasıdır. Ayrıca modellerde kullanılan fraksiyonel derecelerin harici bir sistem parametresi olarak kullanılması, bu sistemlerin tasarımında ve kontrollerinde ek bir esneklik sağlamaktadır. Kaotik sistemler başlangıç koşullarına ve sistem parametrelerine hassas bağımlı yapılar olduklarından; bu sistemlerin fraksiyonel dereceden ifadelerle tanımlanmaları, analizlerinde ve kontrollerinde ek bir avantaj sağlayacak ve farklı dinamiklerin oluşmasına dahi imkân verebilecektir [3].

$\mathrm{Bu}$ çalışmada kaos konusuna öncülük eden meteorolog Lorenz'in 1963 yılında sıvılardaki türbülans hareketi ile ilgili yapmış olduğu çalışmalar sonucunda literatüre kazandırılan kaotik Lorenz Sistemi'nin fraksiyonel versiyonu üzerinde durulmuştur [4]. Öncelikle, fraksiyonel dereceden üç adet durum denklemi ile tanımlanan bu sistemin kararlılık analizleri yinelenerek, sistemin kaotik davranış sergileyebileceği minimum fraksiyonel derece belirlenmiştir. Ardından, fraksiyonel derece ile tanımlı diferansiyel denklemlerin nümerik çözümü için kullanılan en yaygın yöntemlerden biri olan Grünwald-Letnikov (G-L) fraksiyonel türev yöntemi ile sistemin nümerik yanıtları elde edilmiştir [5].

G-L yöntemi nümerik yanıtların incelenmesi hususunda başarılı olmasına rağmen, sistemlerin devre gerçekleştirimi çalışmalarında önceki durum bilgilerinin tamamına ihtiyaç duymaktadır. $\mathrm{Bu}$ nedenle gerçekleştirim çalışmalarında elverişsiz bir çözüm haline gelmektedir. G-L yönteminin devre gerçekleştirimine aktarımı için, her ne kadar sınırlı hafıza (shortmemory) yaklaşımı gibi çözümler önerilse de, fraksiyonel dereceli sistemlerin donanım gerçekleştirimleri için kullanılan alternatif yöntemler devre karmaşıklığı ve donanım maliyeti açısından daha avantajlı hale gelmektedir. $\mathrm{Bu}$ alternatif yöntemler, genellikle fraksiyonel türev opetratörünü arzu edilen sınırlı bantta karşılayacak olan tam sayı dereceli yaklaşıklık fonksiyonlarının türetilmesine dayanmaktadır. Devre sentezi esnasında ise ilgili yaklaşıklık fonksiyonları R-C, R-L ya da RL-C ağları ile taklit edilebilmektedir [6].

Bu çalışmada fraksiyonel dereceli Lorenz Sistemi'nin devre sentezinde; fraksiyonel dereceli diferansiyel denklemlerin integrasyon işlemini gerçeklemek için standart kapasitörler kullanmak yerine R-C taklit devrelerinin kullanılmış ve bu devrelerin tasarım aşamaları üzerinde durulmuştur. Fraksiyonel dereceli sistemin R-C taklit devreleri ile tasarımı için, Matsuda yaklaşıklık metodu ile üçüncü dereceden transfer fonksiyonu elde edilmiştir [7]. Elde edilen bu fonksiyon FOSTER-I R-C ağına dönüştürülerek, kaotik Lorenz Sistemi'nin devre çözümünde kullanılmıştır. Tasarlanan fraksiyonel dereceli Lorenz Sistemi'nin SPICE devre simülasyonu ile doğrulamas1 yapılmıştır [8-10].

$\mathrm{Bu}$ kapsamda; fraksiyonel dereceli kaotik Lorenz Sistemi'nin tanitılması, denge noktalarının hesaplanması, kararlılık analizlerinin yapılması ve bu analizler sonucunda sistemin dinamiklerini koruyarak doğrusal olmayan davranışlarını sergileyebilmesi için kullanılabilecek minimum frasiyonel derecenin hesaplanması işleminin ayrıntıları Bölüm 2'de ele alınacaktır. Minimum fraksiyonel derecenin belirlenmesinin ardından, Lorenz sisteminin dinamik davranışlarını etkilemeyen bir fraksiyonel derece belirlenerek G$\mathrm{L}$ yöntemi ile nümerik simülasyon sonuçları elde edilmiş ve bu sonuçlar Bölüm 3'te verilmiştir. Bölüm 4'te fraksiyonel dereceli sistemin gerçekleştirimi için kullanılacak olan FOSTER-I R-C ağının oluşturulması için takip edilmesi gereken sürecin ayrıntıları ele alınmış ve SPICE devre simülasyon sonuçları sunulmuştur. Son bölümde ise çalışmadan elde edilen sonuçlar tartışılmaktadır.

\section{Fraksiyonel Dereceli Lorenz Sistemi}

Kaotik ve sürekli-zamanlı dinamik sistemlerden biri olan Lorenz sistemi sıvilardaki konveksiyonu modellemek için sunulmuştur. Üç adet durum denklemi ile tanımlanan sistemin durum denklemlerinden ikisi sıcaklık katsayısı, üçüncüsü ise hız alanı katsayısıdır. Fraksiyonel dereceli Lorenz Sistemi'ne ait eşitlikler Denklem 1'de verilmektedir [4]:

$$
\begin{aligned}
& { }_{0} D_{t}^{q 1} x=a(y-x) \\
& { }_{0} D_{t}^{q 2} y=c x-x z-y \\
& { }_{0} D_{t}^{q 3} z=x y-b z
\end{aligned}
$$


Burada $a, b$ ve $c$ Lorenz Sistemi'nin kaotik dinamiklerini etkileyen ayarlanabilir parametreleridir. Sistemin tamsayı derecede kaotik salınımlar sergilemesi için $a=10, b=8 / 3$ ve $c=28$ olarak ayarlanabilir.

Denklem 1'de verilen Lorenz sisteminin denge noktaları, sistemin durum değişkenlerinin sıfira eşitlenerek çözülmesi sonucunda $\quad E_{1}=(0,0,0), \quad E_{2}=(-8.4853,-8.4853,27)$ ve $\mathrm{E}_{3}=(8.4853,8.4853,27)$ şeklinde hesaplanmıştır. Denklem 1'deki sistemin Jacobian matrisi Denklem 2'deki gibi elde edilmiştir [11].

$$
J=\left(\begin{array}{lrr}
-a & a & 0 \\
c-z^{*} & -1 & -x^{*} \\
y^{*} & x^{*} & -b
\end{array}\right)
$$

Fraksiyonel dereceli sistemlerin kararlık analizleri için Lyapunov üstellerini hesaplama yöntemi elverişsiz bir yöntemdir. Bunun yerine, bu çalışmada Tavazoei and Haeri [32] tarafından önerilen ve kök değerlerinin hesaplanması ile fraksiyonel sistemlerin kararlılık durumlarının belirlenmesine imkân sağlayan yöntem kullanılmıştır. Buna göre; $E_{1}$ için özdeğerler $\lambda_{1,2,3}=(-22.8277,11.8277,-2.6667)$ iken, $E_{2}$ ve $E_{3}$ için özdeğerler $\lambda_{1,2,3}=(-13.8546,0.0940+10.1945 i, 0.0940-$ 10.1945i) olarak elde edilir. Kararlılık şartı için $|\arg (\lambda)|>(q \pi / 2)$ şartı sağlanmalıdır [12]. Buradan şartı sağlayan minimum fraksiyonel derece " $q_{\min }>0.9941$ " olarak elde edilmektedir. Bu çalışma için fraksiyonel derece " $q=0.995$ " olarak seçilmiştir.

\section{Fraksiyonel Dereceli Lorenz Sistemi}

Literatürde fraksiyonel türev işleminin çözümü için Riemann-Liouville, Caputo ve Grünwald-Letnikov (G-L) gibi farklı etkin hesaplama yöntemleri mevcuttur [5]. Burada fraksiyonel dereceli Lorenz Sistemi'nin nümerik simülasyonu için matematiksel tanımlamaları Denklem 3'te verilen G-L yöntemi kullanılmıştır.

$$
{ }_{a} D_{t}^{q} f(t)=\lim _{h \rightarrow 0} \frac{1}{h^{q}} \sum_{j=0}^{\left[\frac{t-a}{h}\right]}(-1)^{j}\left(\begin{array}{l}
q \\
j
\end{array}\right) f(t-j h)
$$

Burada $a$ ve $t$ türev işleminin sınırları iken, $\mathrm{h}$ adım büyüklüğüdür. '[*]' işlemi tamsayı kısmı ifade ederken, binom ifadesinin açılımı Denklem 4'teki gibidir:

$$
\left(\begin{array}{l}
q \\
j
\end{array}\right)=\frac{\Gamma(q+1)}{\Gamma(j+1) \Gamma(q-j+1)}
$$

Denklem 3'te $\mathrm{j}=4000$ ve $\mathrm{h}=0.01$ değerleri kullanılarak $[\mathrm{x}(0)=1, \mathrm{y}(0)=1, \mathrm{z}(0)=1]$ başlangıç koşulları kullanılarak GL yöntemi ile çözülen fraksiyonel dereceli Lorenz Sistemi'ne ait nümerik simülasyon sonuçları Şekil 1'de sunulmaktadır. Şekil 1.a'da $\mathrm{x}, \mathrm{y}$ ve $\mathrm{z}$ durum değişkenlerinin zaman domeni cevapları sunulurken, Şekil 1.b'de x-z faz portresi cevabı verilmektedir.

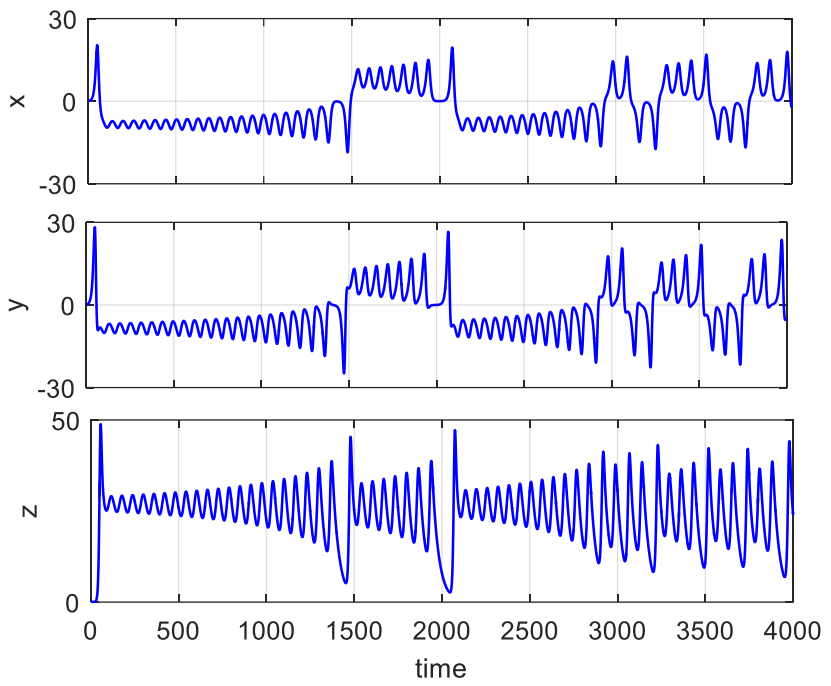

(a)

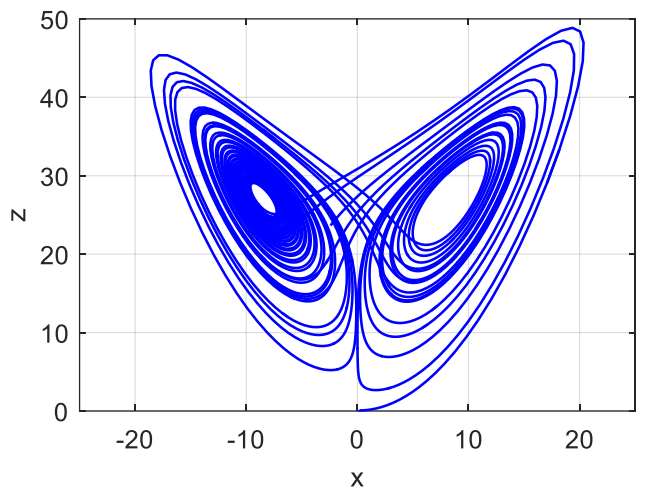

(b)

Şekil 1.Fraksiyonel dereceli Lorenz sistemi'nin G-L yöntemi kullanılarak yapılan nümerik simülasyon sonucu.

\section{Fraksiyonel Dereceli Lorenz Sistemi'nin Devre Sentezi}

Fraksiyonel dereceli Lorenz Sistemi'nin G-L yöntemi ile nümerik yanıtların incelenmesinin ardından bu bölümde fraksiyonel sistemin devre sentezi üzerinde durulacaktır. Daha önce de bahsedildiği gibi fraksiyonel türev ve intregral işlemlerinin nümerik çözümü için geliştirilen yöntemlerin fraksiyonel dereceli sistemlerin devre sentezinde doğrudan kullanılması oldukça güçtür. $\mathrm{Bu}$ sebeple fraksiyonel dereceli sistemlerin donanım gerçekleştirimleri için kullanılan alternatif yöntemler devre karmaşıklığı ve donanım maliyeti açısından daha avantajlı hale gelmektedir. $\mathrm{Bu}$ alternatif yöntemler, genellikle fraksiyonel türev opetratörünü arzu edilen sınırlı bantta karşılayacak olan tam sayı dereceli yaklaşıklık fonksiyonlarının türetilmesine dayanmaktadır [6].

Bu çalışmada fraksiyonel dereceli Lorenz Sistemi için elde edilmesi amaçlanan tam sayı dereceli yaklaşıklık fonksiyonun hesabı için Matsuda yönteminden yararlanılmıştır. Yaklaşıklığın Matsuda yöntemi ile elde edilmesi için iki aşamalı bir hesaplama uygulanır. Öncelikle "sq"nun rasyonel bir modeli sürekli fraksiyonel açılım yöntemi ile elde edilir. Ardından arzu edilen frekanstaki orijinal fonksiyona sabitleme işlemi uygulanır. Sonuç olarak "s" "nun yaklaşıklık fonksiyonu Matsuda yöntemi ile Denklem 5 'teki gibi hesaplanır [7]: 


$$
\begin{aligned}
& s^{q}=d_{0}\left(2 \pi f_{0}\right)+\frac{s-2 \pi f_{0}}{d_{1}\left(2 \pi f_{1}\right)+\frac{s-2 \pi f_{1}}{d_{2}\left(2 \pi f_{2}\right)+\frac{s-2 \pi f_{2}}{\ldots}}} \\
& d_{0}(2 \pi f)=\left|(j 2 \pi f)^{q}\right| \\
& d_{k+1}(2 \pi f)=\frac{2 \pi f-2 \pi f_{k}}{d_{k}(2 \pi f)-d_{k}\left(2 \pi f_{k}\right)} \quad k=0,1, \ldots ., N
\end{aligned}
$$

$\mathrm{Bu}$ yöntemde kutupların ve sıfırların toplam sayısı yaklaşık $\mathrm{N}$ derecesi olarak bilinir.

Matsuda yöntemi kullanılarak $\mathrm{q}=0.995$ değeri için hesaplanan yaklaşıklık fonksiyonu Denklem 6'da sunulmaktadır:

$$
H(s)_{10 n, \text { Matsuda }}^{0.995}=\frac{s^{3}+4.165 \times 10^{7} s^{2}+1.496 \times 10^{12} s+4.109 \times 10^{15}}{0.3924 s^{3}+1.428 \times 10^{4} s^{2}+3.977 \times 10^{7} s+9.55 \times 10^{7}}
$$

Tam sayı dereceden tanımlanmış Lorenz Sistemi'nin ayrık elemanlar kullanılarak donanım gerçekleştirim çalışması göz önüne alındığında, sistemin diferansiyel ifadelerinin gerçekleştirimi için kapasitör elemanının $\mathrm{Z}(\mathrm{s})=1 / \mathrm{sC}$ ifadesi ile temsilinden yararlanılmaktadır. Lorenz Sistemi'nin ayrık donanımla gerçekleştirim çalışmasına örnek teşkil eden bir devre şeması Şekil 2'de sunulmaktadır.

Sistemin gerçekleştirim şeması göz önünde bulundurularak, Laplace domeninde tanımlı olan klasik kapasitör ifadesi ve eşitlikleri, fraksiyonel matematikle tanımlanarak genelleştirilirse $\mathrm{Z}(\mathrm{s})=1 / \mathrm{s}^{\mathrm{q}} \mathrm{C}_{\mathrm{q}}$ tanımlaması karşımıza çıkmaktadır. Bu tanımlama fraksiyonel kapasitör kavramı olarak değerlendirilmekte ve iki terminalli bir eleman gibi düşünülmektedir. Bu iki terminalli yapının değeri $10 \mathrm{nF}$ olan normal bir kapasitör yerine kullanılabilmesi için, $\mathrm{q}=0.995$ fraksiyonel derecesi ve Denklem 6'daki yaklaşıklık fonksiyonu kullanılarak FOSTER-I R-C ağ yapısına uygun şekilde Şekil 3 'teki gibi bir tasarım yapılmıştır [8].

Değeri $10 n F / s^{0.005}$ olan ideal fraksiyonel dereceli kapasitör ve Denklem 6 ile verilen yaklaşıklık fonksiyonunun genlik (Şekil 4a) ve faz (Şekil 4b) yanıtlarının karşılaştırılması Şekil 4 'te sunulmaktadır. İlgili şekillerden de görülebileceği gibi ideal fraksiyonel kapasitörün faz açısı $\pi \mathrm{q} / 2$ ilişkisine bağlı olarak $89.55^{\circ}$ ' de sabitken, yaklaşıklık fonksiyonun faz açısı belirli bir frekans bandı dışında sapmaktadır.

Şekil 3'teki bu tasarımda eleman değerleri $\mathrm{R}_{0}=2.5485 \Omega$, $\mathrm{R}_{1}=40.005 \Omega, \quad \mathrm{R}_{2}=433.7114 \Omega, \quad \mathrm{R}_{3}=43.024 \mathrm{M} \Omega, \quad \mathrm{C}_{1}=749.22 \mathrm{nF}$, $\mathrm{C}_{2}=759.59 \mathrm{nF}, \mathrm{C}_{3}=9.6717 \mathrm{nF}$ olarak belirlenmiştir. Bu R-C ağ yapısının Şekil 2'deki devre yapısına adaptasyonu ile $\mathrm{q}=0.995$ fraksiyonel dereceli Lorenz Sistemi için tasarlanan devre yapısı elde edilmiştir. $\mathrm{Bu}$ devre yapısına ait SPICE simülasyon sonuçları Şekil 5 'te verilmektedir.

Şekil 5'teki simülasyon sonuçlarından görüldüğü gibi $\mathrm{q}=0.995$ fraksiyonel dereceli kaotik Lorenz sistemi için hesaplanan yaklaşıklık fonksiyonu kullanılarak tasarlanan R-C ağ yapısının, tamsayı dereceli Lorenz Sistemi için tasarlanan devre yapısına adaptasyonu ile fraksiyonel dereceli sisteme ait devre yapısı başarılı bir şekilde sentezlenmiştir.

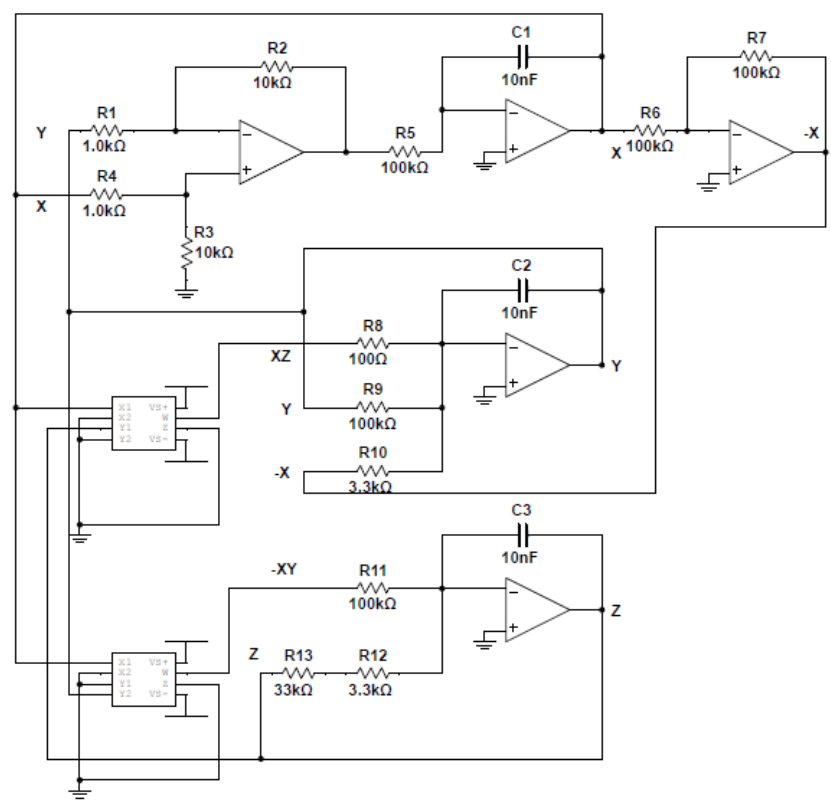

Şekil 2. Kaotik Lorenz Sistemi'nin VOA tabanll opamplar kullanılarak ayrık donanımlarla gerçekleştirim şeması.

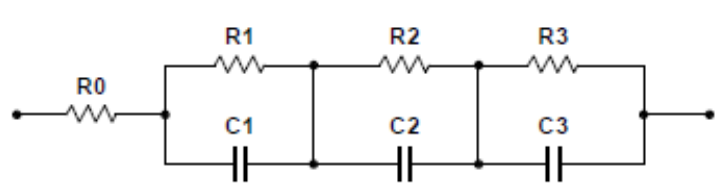

Şekil 3. $q=0.995$ fraksiyonel dereceli $10 n F / s^{0.005 ' l l k ~ k a p a s i t o ̈ r ~}$ için FOSTER-I R-C ăg yapısına uygun tasarlanan devre şeması.

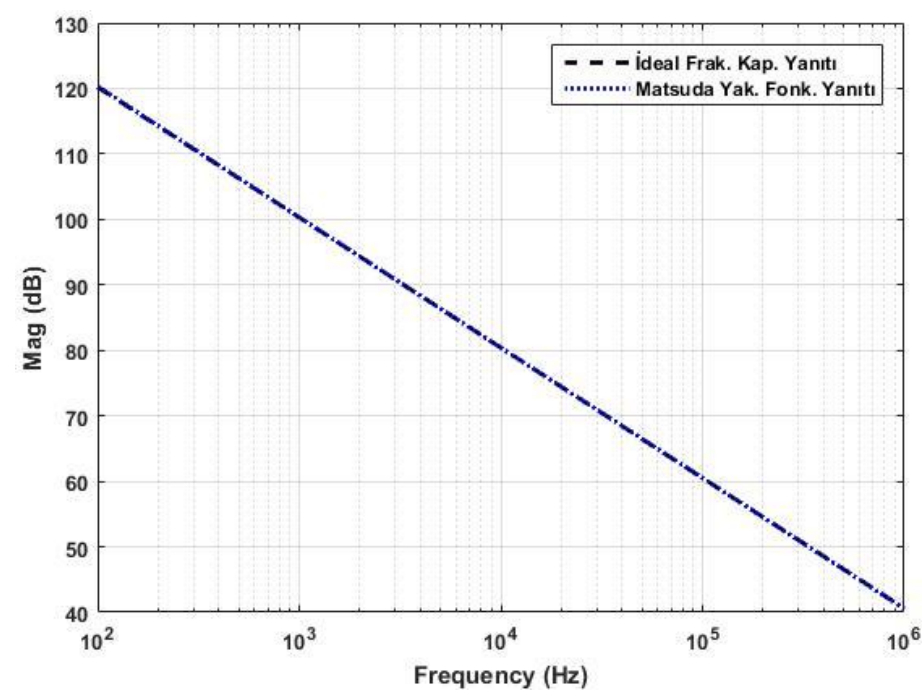

(a) 


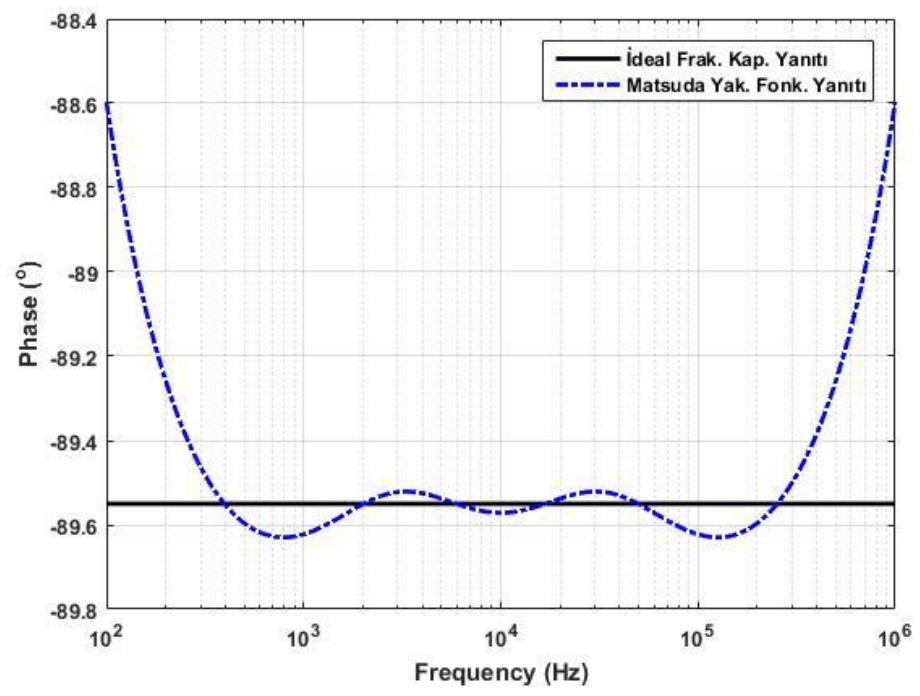

(b)

Şekil 4. Değeri $10 n F / s^{0.005}$ olan ideal fraksiyonel dereceli kapasitör ile yaklaşık fonksiyonunun a) genlik ve b) faz yanıtlarının karşılaştırılması.
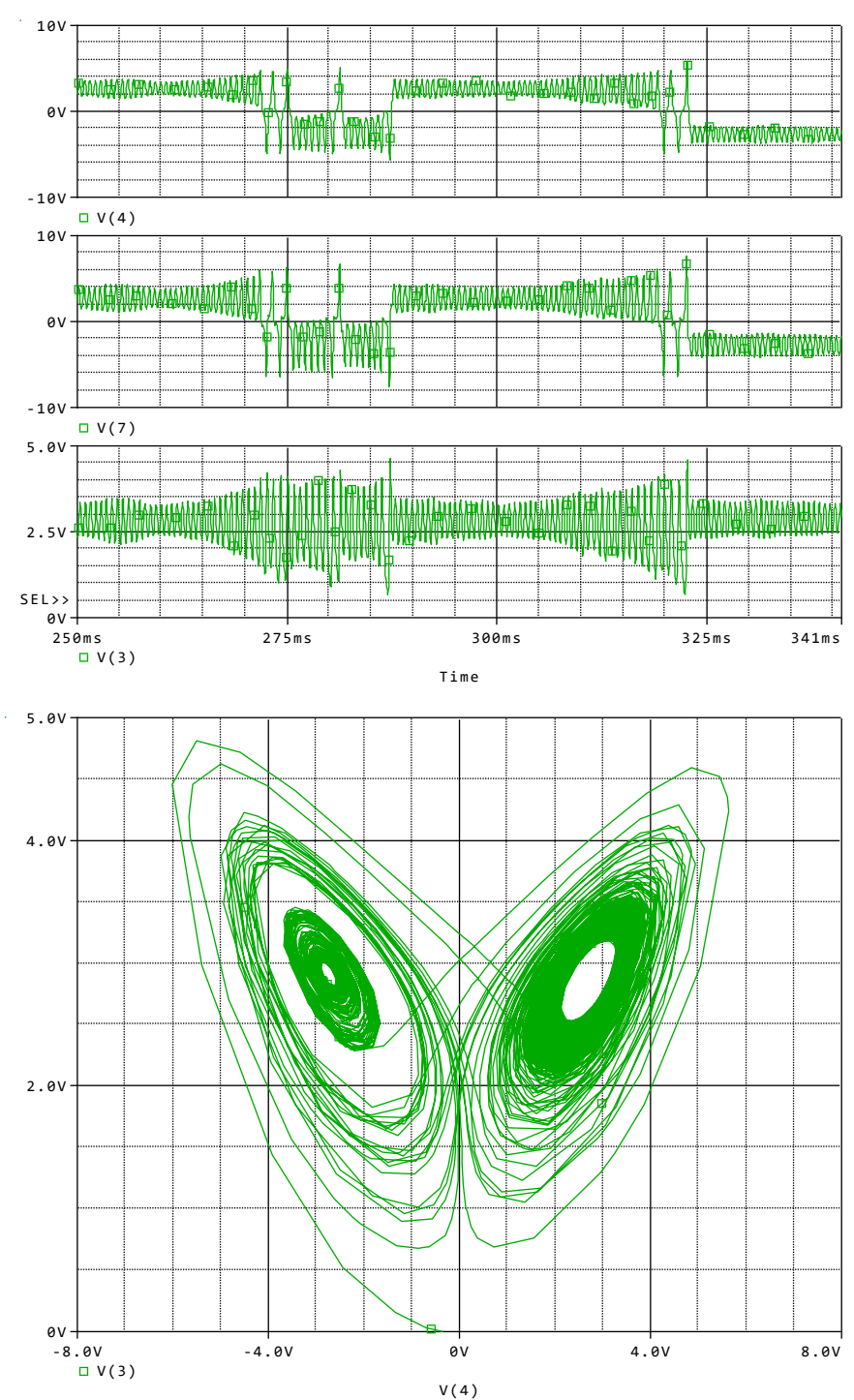

Şekil 5. $q=0.995$ fraksiyonel dereceli Lorenz sistemi'nin FOSTER-I R-C kullanilarak yapllan devre sentezine ait simülasyon sописи.

\section{Sonuç}

$\mathrm{Bu}$ çalışmada fraksiyonel dereceli kaotik Lorenz Devresi için FOSTER-I R-C ağ yapısından yararlanılarak bir taklit devresi sentezi yapılmış sonuçlar SPICE simülasyonu ile test edilmiştir. Bu kapsamda öncelikle kaotik Lorenz sisteminin denge noktaları hesaplanmış, kararlılık analizleri yapılarak sistemin kaotik davranış sergileyebilmesi için minimum fraksiyonel derecesi " $q_{\min }>0.9941$ " olarak elde edilmiştir. $\mathrm{Bu}$ hesaplamanın ardından q=0.995 değeri kullanılarak fraksiyonel dereceli Lorenz Sistemi’nin diferansiyel denklemlerinin çözümü için Grünwald-Letnikov analiz yöntemi kullanılarak nümerik analizi başarılı bir şekilde yapılmıştır. Nümerik analiz sonrasında belirlenen fraksiyonel derece için Matsuda yaklaşıklık yöntemi kullanılarak üçüncü dereceden bir transfer fonksiyonu hesaplanmıştır. Belirlenen transfer fonksiyonunun FOSTER-I R$\mathrm{C}$ ağ yapısı ile gerçekleştiriminin tamsayı dereceli Lorenz Sistemi için tasarlanan devre yapısına adaptasyonu ile bu sistemin fraksiyonel dereceden devre sentezi başarılı bir şekilde yapılmıştır. Sisteme ait devre simülasyon sonuçları nümerik simülasyon sonuçları ile birebir uyumludur.

\section{Kaynakça}

[1] May, R. M., Isham, V., Bolker, B., Renshaw, E., Lawrance, A. J., Spencer, N. M., ... \& Cheng, B. (1992). Discussion on the meeting on chaos. 0035-9246, 54(2), 451-474.

[2] Pamuk, N. (2013). Dinamik sistemlerde kaotik zaman dizilerinin tespiti. Balıkesir Üniversitesi Fen Bilimleri Enstitüsü Dergisi, 15(1), 78-92.

[3] Sacu, I. E., \& Alci, M. (2018). Low-power OTA-C based tuneable fractional order filters. Electronic Components and Materials, 48(3), 135-144.

[4] Lorenz, E. N. (1963). Deterministic nonperiodic flow. Journal of atmospheric sciences, 20(2), 130-141.

[5] Podlubny, I. (1998). Fractional differential equations: an introduction to fractional derivatives, fractional differential equations, to methods of their solution and some of their applications. Elsevier.

[6] Krishna, B. T. (2011). Studies on fractional order differentiators and integrators: A survey. Signal Processing, 91(3), 386-426.

[7] Matsuda, K., \& Fujii, H. (1993). H (infinity) optimized wave-absorbing control-Analytical and experimental results. Journal of Guidance, Control, and Dynamics, 16(6), 1146-1153.

[8] Elwy, O., Rashad, S. H., Said, L. A., \& Radwan, A. G. (2018). Comparison between three approximation methods on oscillator circuits. Microelectronics Journal, 81, 162-178.

[9] Kiliç, R., \& Korkmaz, N. (2016). Experimenting chaos with chaotic training boards. Chaotic Modeling and Simulation (CMSIM), 1, 71-84.

[10] Cuomo, K. M., \& Oppenheim, A. V. (1993). Circuit implementation of synchronized chaos with applications to communications. Physical review letters, 71(1), 65.

[11] Tavazoei, M. S., \& Haeri, M. (2007). A necessary condition for double scroll attractor existence in fractional-order systems. Physics Letters A, 367(1-2), 102-113.

[12] Tavazoei, M. S., \& Haeri, M. (2009). A note on the stability of fractional order systems. Mathematics and Computers in simulation, 79(5), 1566-1576. 